\title{
Assessing Usage And Maximizing Finance Lab Impact: A Case Exploration
}

Magdy Noguera, Southeastern Louisiana University, USA

Michael Craig Budden, Southeastern Louisiana University, USA

Alberto Silva, Southeastern Louisiana University, USA

\begin{abstract}
This paper reports the results of a survey conducted to assess students' usage and perceptions of a finance lab. Finance labs differ from simple computer labs as they typically contain data boards, streaming market quotes, terminals and software that allow for real-time financial analyses. Despite the fact that such labs represent significant and ongoing investments in the learning environment, the results of the survey show that students value finance labs, but fail to maximize their use. Recommendations are made to address this situation.
\end{abstract}

\section{INTRODUCTION}

¿ $\mathrm{n}$ order to respond to the technological needs of students and employers, attract students, and meet and exceed accreditation standards, many business schools have made finance labs available to their students. Employers demand students with computer skills to be successful in their jobs. In the same token, students welcome the usage of internet-based resources, especially for online assignments, as they believe such resources increase their learning experience [Michelson and Smith, 2004; Peng, 2006; Smolira, 2008]. Establishing finance labs makes sense when computer literate students are expected to learn better by doing, rather than in the traditional form [Spinelli, 2001]. Finance professors recognized decades ago that having computer skills was important to the success of finance students [Cudd, Tanner, and Budden, 1989)]. Computer skills that once were deemed adequate have undoubtedly been elevated as the finance profession has become more technology-based. These days, a finance professional relies extensively on computers for financial analysis and trading. That is why exposure to and use of a finance lab can increase students' personal computing and analysis abilities.

In addition, finance labs serve as an important recruiting tool to attract students. Business schools often tout their finance labs as a competitive edge over other schools [Leff, 2008]. Leff reports that finance labs will allow students to develop competencies they will need for careers in finance; as they become familiar with the analytical tools and software commonly used in Wall Street and corporate finance institutions.

Finally, business schools typically use their finance labs to further their efforts to meet and exceed accreditation standards. The Association to Advance Collegiate School of Business International's (AACSB) Eligibility Procedures and Accreditation Standards (www.aacsb.edu/accreditation/AACSB-Standards-2010.pdf) has expectations that business schools will innovate in instructional processes, provide students with engaging learning opportunities through technology-based tools (Standards 13 and 14), maintain faculty sufficient to provide stability and ongoing improvement for the instructional programs offered (Standard 9) and meet intellectual contribution expectations (Standard 5). The standards expect business schools will ensure technology support for students and faculty exists and is appropriate to provide ongoing engagement with students (Standard 14) and allow faculty to progress in their careers (Standard 11). As can be surmised, the myriad ways in which a finance lab can address accreditation expectations is a major benefit of such a lab.

When used as intended, finance labs provide many benefits despite representing a considerable investment. In 2006, a small lab boasting advanced capabilities could cost $\$ 200,000$ to establish [Duggal, 2006]. Today, a stateof-the art lab can be much more expensive. For example, The Pitt's Joseph M. Katz Graduate School of Business cost 2.3 million dollars in 2008 [Leff, 2008]. In addition to the fixed, typically one-time costs of establishing a lab, 
the costs of staff, maintenance and recurring license fees need to be considered. These costs can be daunting, especially in tough economic times. In light of the acquisition and operating costs of such labs, and the educational goals associated with finance labs, it is important to gather, analyze and respond to feedback of finance lab users so that maximum returns may accrue from the investment. This is the main objective of this paper. Furthermore, recommendations based on students' input are made to increase the level of use and efficiency in the use of finance labs.

\section{THE FINANCE LAB}

At the subject institution, the finance lab hardware consists of computer terminals, two data boards located inside the room and one electronic ticker tape located at its entrance. The data boards provide real-time data in indices, treasury security prices, foreign exchange rates, and stock quotations. The ticker provides current selected indices and stock market data. The lab contains 40 computer (PC) terminals and one Bloomberg terminal.

The software includes PC software (spreadsheet, presentation, and statistical analysis software) and specialized software, such as Bloomberg and Financial Trading Software (FTS). The finance lab has one Bloomberg terminal from which Bloomberg Services can be accessed. Bloomberg Services is a source of real-time and historical financial news and information that allow Bloomberg's customers to trade, conduct research, and communicate. Through Bloomberg, students can access current and historical information on stocks, bonds, foreign currencies, derivatives, and other financial instruments, in addition to news and prepackaged analytics. Bloomberg current and historical data can also be downloaded to Excel for customized analysis.

In addition, a subscription to Bloomberg allows both faculty and student access to the Bloomberg training/certification program. Bloomberg offers equities and fixed income certifications that require watching videos and passing 9-15 multiple choice question exams [Scott, 2010]. Persons successfully completing the program receive Bloomberg certification. Since the lab's establishment in 2006, only two faculty members have been certified through the lab in the subject institution, with only one of the certified faculty members remaining on the finance faculty. Along with a total lack of student completers (certifications), the situation is a disappointing reality and stands as a challenge to the lab's promoters.

The other software available in the finance lab for teaching finance courses is the Financial Training Software (FTS). FTS is a web-based package that offers students a local and live trading environment to perform case-based trading. As a simulation program, FTS is a valuable addition to the finance lab as researchers have found that students perceive the use of an investment simulation made finance classes a more interesting learning experience [Burns and Burns, 1982] and increased student learning [Weiser and Schug, 1992]. FTS has standard cases on Fixed Income, Diversification and Capital Asset Pricing Model, Binomial Option, Option Hedging, and Market Efficiency.

In the subject institution, the lab was established with an outside grant. The lab cost approximately $\$ 200,000$. Afterwards, recurrent maintenance and subscription costs have been incurred. For example, the annual licensing fee for the FTS was $\$ 7,500$ in 2006. Currently, the fee for Bloomberg access is $\$ 1,900$ per month which makes it an expensive resource. However, the administration approved a departmental/college request to establish a finance lab fee that is added to the tuition of each finance course. This fee allows the department to cover current software and subscription renewals and provides for the maintenance of the lab. It was the first and is still the only fee specifically approved for the department's/college's benefit.

Given the significant investment on it, access to the finance lab is restricted. Students may use the lab during classes and under faculty supervision only. Lack of financial resources does not allow the college to hire and maintain lab attendants for access and tutoring outside of class time.

\section{METHODOLOGY}

A survey of students enrolled in 13 finance classes offered in the College of Business in the Fall 2009 semester at a University in the Southeast was conducted to ascertain perceptions of its finance lab and to assess its 
impact on the learning environment. Of the 13 classes, 12 were undergraduate classes (junior and senior level) and one was offered at the Master's level. A total of 332 students responded to the survey resulting in 319 usable responses. The anonymous questionnaire was administered immediately prior to each class's scheduled start time by researchers who did not distribute the questionnaires in classes in which they were teaching so as to minimize bias and encourage honesty among respondents. The questionnaire contained 41 questions divided into three sections: a demographics section, a section to assess specific lab usage questions, and a section to gauge students' perceptions of the finance lab itself.

\section{RESULTS}

Approximately $51 \%$ of the respondents were male and $49 \%$ female. This is almost identical to the College's 2009 Fall enrollment of $50.4 \%$ male and $49.6 \%$ female. Ninety percent of the respondents were full-time students. More than half (56\%) reported being between 22 and 24 years of age, $17 \%$ were 21 years old or younger, and the remaining $27 \%$ reported being at least 30 years of age. These descriptive statistics suggest that respondents were mostly traditional students who should be familiar with computers as they were raised in a technological age. Most of the respondents were majoring in an area of business. Those majoring in General Business represented 22.8 percent of the respondents, closely followed by Finance majors (21.8\%), Management majors (17.3\%), Accounting majors (12.7\%), and Marketing and Supply Chain Management majors (6.2\%). MBA students represented $12.7 \%$ of the respondents. Non-business major represented $6.6 \%$ of the respondents. As far as student classification, 54\% of the respondents reported they were seniors, 33\% reported being a junior, while approximately $13 \%$ were graduate students. As a result, the sample was representative of a broad diversity of business students who are both eligible and required to take finance courses.

\section{REPORTED LAB USAGE}

Finance classes are taught in the lab so students are familiar with and use the lab. Table 1 reports students' usage of the software in the finance lab.

Table 1: Percentages of Respondents using Software (by Response Options)

\begin{tabular}{|l|c|c|c|c|}
\hline \multicolumn{1}{|c|}{ Software } & Never used & Rarely & Regularly & $\begin{array}{c}\text { I don't know about } \\
\text { this resource }\end{array}$ \\
\hline Microsoft Excel & 10.5 & 17.8 & 69.2 & 2.5 \\
\hline Microsoft PowerPoint & 27.1 & 21.8 & 47.9 & 3.2 \\
\hline Ticker/DataBoards & 36.6 & 25.8 & 23.6 & 14 \\
\hline SPSS & 46.3 & 14.5 & 2.6 & 36.7 \\
\hline Finance Websites (Yahoo, Google, others) & 44 & 21.9 & 24.9 & 9.2 \\
\hline Bloomberg & 50.3 & 18.8 & 4.5 & 26.4 \\
\hline Financial Trading System (FTS & 49.2 & 19.4 & 4.4 & 27 \\
\hline
\end{tabular}

As far as the use of specific lab resources, students reported they were familiar with and used Excel and PowerPoint as they are required to use Excel to address financial analysis assignments and PowerPoint for their presentations. Ostensibly, student use of these resources may be due to the high incidence of faculty who use these packages in class [Cudd, Lipscomb, and Tanner, 2003].

The electronic ticker tape located outside the lab at the College of Business building's main entrance is quickly noticed by all who enter the building. Inside the finance lab, all students sit facing the data board. Regardless of their prominence, the ticker and data boards were used by only about one-half of the respondents. The statistical package, SPSS, was reported to be used by $17 \%$ of the respondents. More than $50 \%$ of the students reported being familiar with the Yahoo and Google finance websites. These results are somewhat consistent with the idea that finance websites are very useful to teach finance courses. However, overall, it is troublesome that one-half of the respondents have not used the ticker, the data boards, or several finance websites recommended for use in the lab. 
A bigger disappointment to the researchers was the finding that the Bloomberg terminal and the Financial Trading System (FTS) software were either unknown to or reportedly never used by $76 \%$ of the respondents. Reported use of Bloomberg and FTS differed by major. In the case of the Bloomberg terminal, 88\% of the respondents who were in the Principles of Finance class (the entry level finance class where students are first exposed to the finance lab) and $89 \%$ of the graduate student respondents did not know about or had never used Bloomberg. Of those who knew or ever used Bloomberg, 55\% were finance students and $63 \%$ were respondents taking two or more finance courses. Thus, the survey indicated a knowledge gap about Bloomberg between those students taking the first finance course only and students taking multiple finance courses (mostly finance majors). A possible explanation for these findings is that both the Principles of Finance course and the MBA finance course are the only finance courses required for business majors in their respective curricula and they may have little time to cover the basics and get familiarized with the finance lab. Still, it was expected that students would be familiar with these resources since the survey was conducted at the end of the semester in which they had used the lab.

The case of FTS resource utilization was slightly better as far as respondent familiarity with the software. Of the respondents enrolled in the Principles of Finance class, 78\% reported they did not know about FTS or had never used it. Among graduate students, $86 \%$ did not know about or had never used FTS. Thus, compared to the case for Bloomberg, some students were aware of the existence of the software, perhaps because students, out of curiosity, have accessed it through a link located in the desktop of all lab computers. Interestingly, the usage level was lower than expected among finance students as only $37 \%$ reported using it and also, about $42 \%$ of the respondents taking two or more finance classes were familiar with it. These results seem to indicate that the FTS program is used in few classes by some of the finance faculty. Overall, the results suggest that of the few who know or have used Bloomberg and FTS, most are finance majors.

As indicated in Figure 1, the more popular uses of finance lab resources revolved around e-mail (54.2 percent) and online surfing (29.6 percent). Using the lab to conduct financial research (27.8\%) came in third. To a lesser extent, respondents reported other non-course uses of the lab, including Facebook/Twitter (22.8\%) and online chatting (8.2\%). Given the respondents' answers, it is clear that a major use of the lab is not class related. This is confirmed by $84 \%$ of the respondents who affirm they have seen other students using the computers for activities other than finance-related classes.

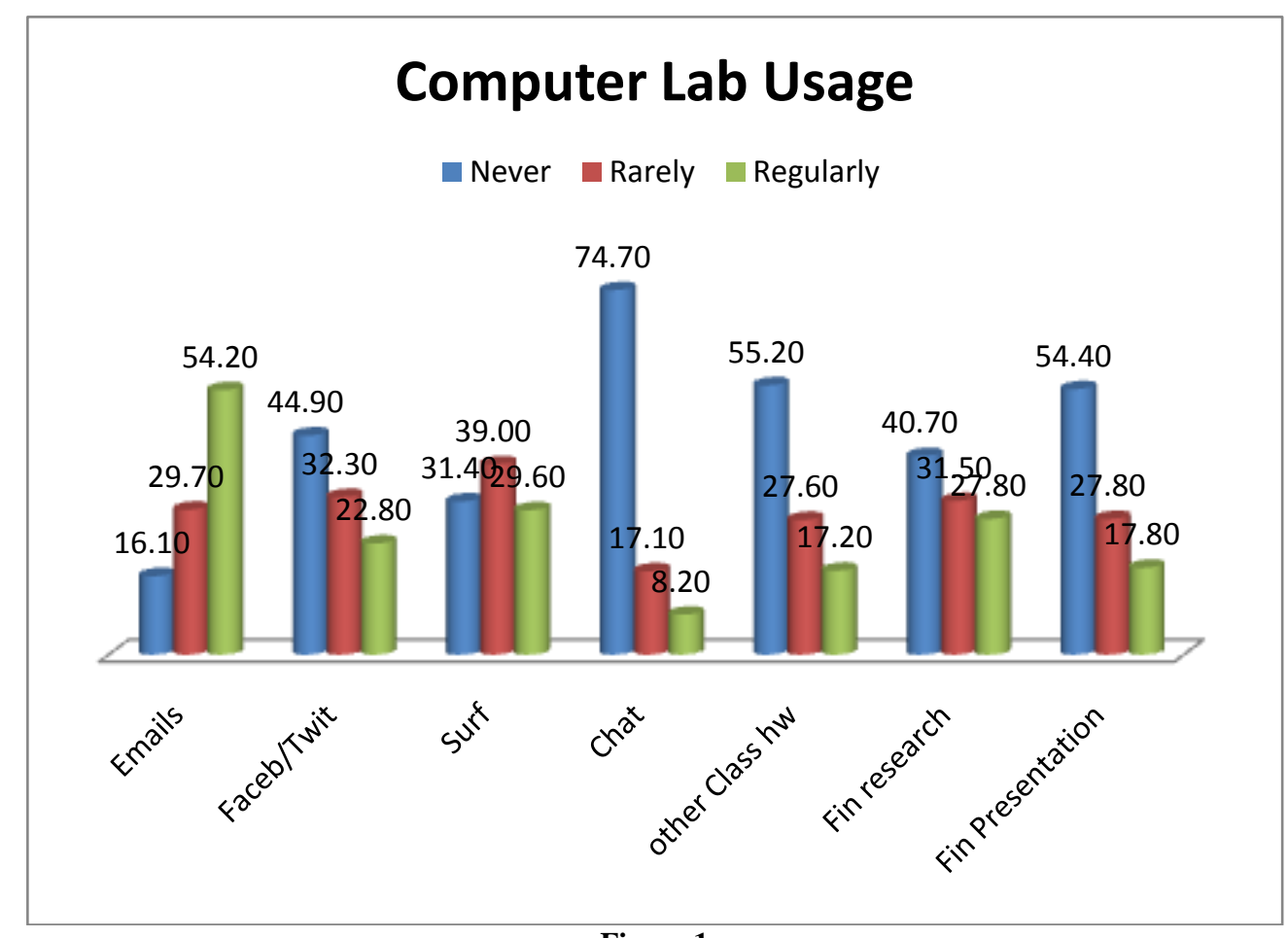

Figure 1 
When students are asked whether they use the finance lab to conduct finance research projects, prepare finance presentations, or finish homework for other classes, the survey reveals that around $60 \%$ use the lab to conduct finance research projects, but less than $50 \%$ of the students use the lab to either prepare finance presentations or finish homework for other classes. The use of the finance lab by students to complete finance projects during class time is a problem since such endeavors take students' attention away from class. It would be better if students could complete their projects at other times.

In fact, $55 \%$ of finance majors claim that they need access to the finance lab outside class time and $67 \%$ would spend more time in the lab, outside class periods, working on finance-related activities if they had such access. Business students opined that the lab should be opened more and should have lab attendants capable of offering assistance. These expectations appear reasonable as the lab is open during class time only, and even then, there is only one Bloomberg terminal.

\section{STUDENTS' PERCEPTIONS ABOUT THE FINANCE LAB}

Students were asked whether or not the use of the finance lab would improve their career efforts and also to indicate in which areas of finance (investments, corporate finance, etc.) their understanding will be increased by using the finance lab. In addition, respondents indicated their level of agreement with statements concerning students' opinions about how using the finance lab would contribute to their career goals. Students were also asked for recommendations on how to improve the use of the finance lab.

Approximately $91 \%$ of the finance students and more than 55\% of all majors believe their use of the finance lab would improve their career efforts. Seventy-nine percent of all respondents believe their understanding of all finance areas will increase by using the finance lab. Students believe the finance lab will impact their academic formation and their careers favorably. Sixty-four percent of the students believe they can handle a project when using finance lab resources. The majority of respondents believe that a finance simulation class, a project or homework would improve their understanding of finance (69\%) and prepare them better for their career (64\%). Finance majors appear to appreciate the finance lab the most while students taking only the Business Finance Principles class have the lowest appreciation for the lab. Clearly, students, regardless of major, have an appreciation for the finance lab, but their current use of the lab does not match such expectations.

The main example is the case of the Bloomberg certification. The business school pays a substantial monthly subscription fee to have a Bloomberg terminal. The terminal allows faculty and students to seek certification through the lab. However, only $17 \%$ of all respondents reported they were encouraged to obtain Bloomberg certification. Of those who were encouraged to seek certification, $42 \%$ were finance majors. Forty-eight percent of all respondents expressed the need for instructions on how to obtain it, especially among finance majors (60\%). More worrisome yet, most students (except finance majors) are indifferent about obtaining the Bloomberg certification $(40 \%)$ and doubt its value (43\%). The lack of knowledge, motivation, and access to the lab explain the fact that, to date, no student is known to have obtained certification through lab resources. This situation represents a challenge and an opportunity.

\section{RECOMMENDATIONS}

Many respondents were unfamiliar with lab resources. To address this problem, finance faculty and departmental and school administration need to be involved in the promotion and use of the finance lab. Several specific recommendations are proposed based on the findings of the study.

First, goals need to be set to assure impact on the learning environment. Goals that may be set for the use of the lab may include the number of open hours available to students, student utilization, and faculty utilization. Further, the number of students (and faculty) who can be expected to seek and obtain certification needs to be established. Only by having concrete numerical goals can adequate assessments of impact be accomplished. And yes, having goals as to faculty certification levels is important. If use of the labs and certification levels by students are deemed important to assure learning, then surely faculty can be expected to become proficient to the point of certification. Widespread certification of the faculty would allow faculty to lead by example. Student awareness of 
the importance of certification to faculty will encourage them to seek certification as well. Faculty may initially be reticent to learn and incorporate lessons based on the finance lab resources into their curricula. After all, it would take time from teaching, research, and service. However, the authors believe that by better understanding lab resources, faculty will be able to advance their teaching, their professional goals and their continuing intellectual development.

Second, a user handbook should be developed and distributed. The authors believe a handbook extolling the lab and its resources should be distributed to students in both the Principles course and the MBA course. After all, over $60 \%$ of respondents indicated they were willing to participate in finance simulations and complete projects and/or homework through the lab. Having available a concise handbook detailing lab resources and the use of such resources would allow students to better assess the appropriateness of applying lab resources to their efforts. Indeed, as faculty prepare the handbook, they, too, will become more aware of what the lab offers and hopefully be encouraged to make maximum use of its resources and to seek certification as well. The handbook could be utilized in a lab orientation setting to better prepare students for lab use.

Third, a lab orientation should be offered at the beginning of each semester to introduce finance lab resources to finance students. This orientation should include the importance of certification and should encourage students to seek it. More than $30 \%$ of respondents indicated they were interested in certification, but did not know how to obtain it. Again, the handbook could and should contain information on certification. The orientation should also instruct students on how lab resources could be brought to bear to serve non-finance course needs of students. For instance, the lab has significant resources that can be used in business policy courses, marketing courses, accounting courses, etc.

Fourth, open lab hours need to be established and monitored. The realization that the lab is closed much of the time limits students' use of the lab and its potential impact on their knowledge and careers. To receive certification students must have access to the Bloomberg terminal at times other than class time to study tutorials and take the exams that lead to certification. Indeed, having only one terminal creates a significant bottleneck. Restrictions on use preclude students from having significant access to the terminal and result in less than optimal use of the resource. As in the case of accounting labs, an increase of lab hours, consistent location, and better promotion of the labs may encourage students to visit the lab [Arnaudovska, Gonzalez, Tumblin, and Budden, 2009].

Finally, university budget situations will affect lab funding. To ensure the ongoing operations of finance labs, schools that establish finance labs need to be aware of the need to establish a continuing source of support for the lab. The initial cost of lab establishment can be daunting, but it is the ongoing costs associated with lab maintenance, assistants, subscriptions and operations that need to be recognized and planned before the investment outlay associated with a lab's establishment. Such continuing support will assure that the lab is situated to provide maximum use and impact by students and faculty. Finally, to decrease the misuse of the finance lab, website restrictive software could be installed on all lab computers. Website blocking software packages allow faculty to control access to the internet from the podium. This would be especially welcome during class time as students would be given access only to websites deemed appropriate for the course. Libraries have successfully employed such software to deter students from freely surfing the web in computers assigned for browsing library catalogs.

Note: it is reasonable to assume that the survey's findings cannot be generalized. However, this study can serve as a reference study, to be conducted in other institutions to assess the cost/benefit of other finance labs. The recommendations are also applicable to other schools as access, support and encouragement of lab resource utilization would universally improve the impact of such labs.

\section{REFERENCES}

1. Association to Advance Collegiate Schools of Business International (AACSB). Eligibility Procedures and Accreditation Standards for Business Accreditation, last revised January 31, 2010. www.aacsb.edu/accreditation/aacsb-standards-2010.pdf. 
2. Arnaudovska, E., L. Gonzalez, W. Tumblin, and M.C. Budden (August 2009). "Issues Surrounding Accounting Lab and Online Accounting Resource Implementation." American Journal of Business Education, 2, 1-6.

3. Burns, W. and M. Burns (Fall 1982). "The Use of Portfolio Management Simulation as a Learning Device," Journal of Financial Education, 79-82.

4. Cudd, M., T. Lipscomb, and J.R. Tanner (May/June 2003). “Technology in the Classroom: An Assessment of Hardware and Software Use in Finance Instruction," Journal of Education for Business, 244-248.

5. Cudd, M., J.R. Tanner, and M.C. Budden (Fall 1989). "The Issue of Student Preparedness: Perceptions of Finance Professors," Journal of Financial Education, 60-64.

6. Duggal, R. (2006). "The Costs and Benefits of a Finance Lab”, Journal of College Teaching and Learning, $3(11), 81-84$.

7. Leff, A. (August 19, 2008). “New Finance Lab in Mervis Hall to Simulate Global Financial Markets,” Pitt Chronicle.

8. Michelson, S., and S. D. Smith (Spring 2004). "Web Usage in Financial Education', Advances in Financial Education, 2, 10-21.

9. Peng, Z. (2006). “Applying Internet-Based Technologiesto Teaching Corporate Finance and Investments." Journal of Educators Online, 3(6), 1-18.

10. Scott, R. Spring-Summer 2010). "Bloomberg 101.” Journal of Financial Education, 80-88.

11. Smolira, J. (2008). "Student Perceptions of Online Homework in Introductory Finance Courses," Journal of Education for Business, 90-94

12. Spinelli, Michael A. (September/October 2001). "The Use of Technology in Teaching Business Statistics." Journal of Education for Business, 77(1), 41-44.

13. Weiser, L. and M. Schug (November-December 1992). "Financial Market Simulations: Motivating Learning and Performance." Social Studies, 244-247. 
NOTES 